\title{
Multicultural Competence in a Study Abroad Program: A Case Study in Fitness for Profession
}

\author{
Carly L. Redding", Michallene G. McDaniel \\ Department of Sociology and Human Services, University of North Georgia, USA
}

\begin{abstract}
This paper discusses the importance of fitness for the profession in applied programs within the context of international field placement. Using a study abroad trip to an impoverished community in India as a case study, the authors describe the difficulties presented by a field setting in which students' cultural competence is particularly challenged. For one student who used the trip to complete service learning requirements prior to graduation, the field setting proved to be overwhelming, despite his having received the same orientation prior to travel as all other participants and after successful completion of academic coursework. We discuss the importance of fitness for the profession, including elements of cultural competence, and its potential relationship to the development of multicultural competence.
\end{abstract}

Keywords International Service Learning, Cultural Competence, Multicultural Competence, Study Abroad in India, Fitness for the Human Service Profession, International Field Placement

\section{Introduction}

An individual's fitness for the profession is a vital concern for those considering entering any applied field of study, as well as for those who supervise nascent human services professionals. Broad and rigorous field experience exposes human services students to many of the common challenges they are likely to encounter later in their professional careers, such as dealing with difficult personalities, making ethical decisions, and prioritizing which service among several a client may need first. Human services faculty members, as experienced educators and practitioners, guide students through a variety of typical challenges during the field experiences built into many human services academic programs.
Participation in study abroad experiences is a growing trend in U.S. higher education (IIE, 2015), and allows academic supervisors a unique opportunity to view and guide students through uncharacteristic challenges that they would not likely experience within a typical domestic field placement. Yet, given the increasing diversity of the United States population, and the broad range of work settings in which human services professionals are employed, exposure to field service work outside a student's everyday milieu may be helpful in preparing them to handle a great number of professional challenges.

Experiential learning and global, multicultural competence, manifest goals in study abroad programs, are important for a better understanding of how students learn and implement creative and critical skills within the field of human services. Additionally, study abroad programs address fitness for the profession issues by allowing supervisors to view students' abilities to behave and communicate effectively and appropriately within different cultural environments. Furthermore, study abroad programs allow supervisors a distinct observational opportunity into students' own perceptions of cultural differences (Hovland, 2010).

So what happens when students who have been productive and academically successful in the classroom (and in local field placement settings) attempt to transfer their skill sets into a very different culture? This paper is an account of an experience of a group of human services students and instructors on a month-long study abroad trip within the slum communities of India. Insights into problems, crises and successes witnessed throughout the experience are discussed. The paper includes a description of what happened upon our group's return from India, and a discussion of how miscommunications and inappropriate behaviors may have been prevented with clearer guidelines for recourse. We conclude with a brief discussion of the importance of fitness for the profession guidelines and policies within our relatively young human services program, and the ways in which problems with cultural competence may foreshadow problems with multicultural competence in the field abroad. 
Where possible, direct identifiers have been removed in order to afford some degree of anonymity to the individuals being discussed in this paper.

\section{Study Abroad and Multicultural Competence}

The growth in study abroad programs in post-secondary education has been accompanied by expanded research on the connections between students' participation in such programs and their development of different types of cultural competence. While the terms cultural competence, cross-cultural competence, inter-cultural competence, and multicultural competence have slightly different definitions, depending on the reference (Rasmussen \& Sieck, 2015), we employ a definition which distills the common components from Pope-Davis, Reynolds, Dings and Ottavi (1994). This definition asserts that multicultural competence is "the ability to work and be effective with individuals who are of a different culture from yours [and includes an] appreciation of and sensitivity to the history, current needs, strengths, and resources of communities and individuals who historically have been underserved and underrepresented."

While some studies have suggested that study abroad programs have substandard results at increasing students' cultural competence (Wong, 2015), research on service-learning study abroad programs indicates a significant increase in students' cultural competence and cultural awareness (Krishnan, Richards \& Simpson, 2016). In fact, Krishnan et al (2016) suggest that short-term study abroad programs that include a service learning component have an increased impact on students' academic and civic learning, specifically in the area of cultural competence. This seems particularly true when the students are involved in meaningful community engagement while abroad. Furthermore, Earnest, Rosenbusch, Wallace-Williams and Keim (2016) found that the inclusion of experiential learning abroad assists students in developing better emotional resilience, perceptual insight and cultural adjustment that promotes student cultural competencies.

In a review of study abroad literature, Edmonds (2011) found that many students report an increase in both insight and cultural sensitivity while participating in immersion experiences abroad, and that such experiences allowed students to more clearly understand and discuss cultural ideas and practices. In addition, Edmonds (2011) discovered that students consistently reported an overall global awareness, became more enlightened, and felt more appreciation for their own socioeconomic status, particularly when working in areas of extreme poverty. These results appear to be consistent over service learning study abroad programs, even in cases of short-term (week long) programs.

\section{Our Human Services Program: Background and Academic Requirements}

Our undergraduate institution in the Southeastern United States developed a human services bachelor's degree program that first began offering classes in August 2010. There were twelve students in the first cohort to graduate from the program in May 2012. Since that initial class, nearly 180 students have graduated from our program (as of May 2017). Most are employed in human services professions, both in the non-profit and corporate sectors, and several have gone on to graduate programs in public health, law, mental health and social work.

One of the most frequently-cited features of our academic program that contributes to student success in the job market is our emphasis on service learning. Students are required to complete four semesters of service learning practice. During their first semester in the program, students receive an introduction to service learning and perform fifty (50) hours of field placement. In each of the three subsequent semesters, students are required to perform two hundred (200) service hours, for a total of 650 service learning hours as a requirement for graduation from the program.

Beginning in June 2014, interested students had the option of completing 200 of their required service learning hours, in addition to other coursework, while on a month-long study abroad trip to India. Most of the students participating in the trip during the first year were very close to graduating from the program, and we anticipated that they would have a relatively high degree of cultural competence. The leaders of the India trip understood the importance of this competence, given the impending challenge to students of negotiating communities of extreme poverty, religious diversity, and very different family and gender norms. The students would be challenged to transfer their cultural competence into true, multicultural competence, in order to successfully complete their month-long stay in India. In fact, most of the students who have participated in this study abroad program over the years have possessed (or developed in the field) such competence. What follows is an account of one student who did not demonstrate cultural competence, did not develop multicultural competence, and the problems that ensued.

\section{Introduction to Our Study Abroad Program}

As mentioned above, study abroad experiences are a growing trend in higher education. These unique educational opportunities allow human services professionals to supervise students in real world situations that are not typical within traditional, domestic field placements. Specifically, faculty members are able to focus on the cognitions, emotions and behaviors of students within a global, multicultural context. 
The study abroad program discussed in this paper focuses on research which assesses and explores maternal attitudes about various topics including children's gender roles, education, discipline, nutrition, and what are considered normal and abnormal behaviors for young children living in a small impoverished Indian community. The assessments conducted by students and faculty allowed researchers to gather information necessary to provide members of this community with much-needed resources they had lacked. Additionally, researchers (including students) conducted home observations between mothers and their infants. These observations are being used by researchers to define maternal attachment within this cultural context, and help identify possible predictors between maternal attachment and cognitive development.

While working in India, researchers noticed an unusually large number of children suffering from behavioral and emotional difficulties. Upon exploration, we discovered many of the children experienced very strict, overly-structured and abusive home environments (by United States standards). After evaluation and discussion with educational leaders in the community, it was determined that pre-school education was a needed resource, as it offered a way to bridge the gap between future educational opportunities and children who may not be offered those opportunities due to being considered at-risk of developing poor psychological health.

The community in which we worked is extremely impoverished, and consists of mostly Hindu nuclear families in a densely populated area. The residents have little to no access to community resources such as law enforcement or governmental protection. The average monthly household income in this community is equivalent to approximately seventeen US Dollars. This level of extreme poverty and lack of educational resources places many of the women and children in this community at risk of becoming trafficked into India's thriving sex industry (Lee, 2011). The overall goal of this study abroad project is to assist community leaders and the local educational director in continuing to develop pre-K classrooms that are high in both emotional and instructional support for at-risk children.

Numerous researchers have documented the benefits of service-learning and research to students, faculty, institutions and communities (Davis, Major, Cook and Bell, 2015). Both research opportunities and service learning experiences improve student learning outcomes and contribute to students' personal and social development. Likewise, it has been suggested that service and research opportunities increase student retention. This project provides opportunities for both service learning and research to students in a community setting characterized by high rates of female infanticide, sexual exploitation, educational dropout, hunger, extreme violence, a lack of protection by law enforcement and lack of representation in one of the largest democracies on earth. To become successful in a new and globally competitive world, human services students need a dedicated work ethic, a passion for learning, creativity, and well-developed problem-solving abilities. These abilities are strengthened with active and applied learning opportunities. This learning approach allows students to analyze global affairs that affect the field of human services by examining the political, economic and cultural issues from historical, psychological, and social perspectives. In addition to gaining first-hand knowledge of problems faced by individuals living in impoverished communities and nations, this experience provides opportunities to develop skills to produce change among these populations across the world and closer to home. Furthermore, faculty supervisors are afforded the opportunity to view students' connections between curriculum, critical thinking and problem-solving skills through integration and active learning on a global scale.

\section{Study Abroad Orientation}

As part of the study abroad program, students are required to attend two of three orientation sessions. The first orientation is an overview of what to expect and students are allowed (and encouraged) to bring family and friends who may have questions regarding the trip. Travel to India seems particularly daunting to many family members of the students at our institution, given that many of our students have little domestic travel experience. In fact, many have never traveled by airplane prior to the India trip. Given this, the orientation sessions to the India trip cover all of the basics of international travel: weather conditions in coastal India during monsoon season; cultural issues, such as appropriate dress and behavior; and daily schedules the students should expect to encounter while abroad. During this orientation, rules and regulations provided by the host organization (the non-government organization that houses students and faculty in India) are also reviewed. This orientation is not mandatory, but is highly recommended.

The second orientation is specifically for those attending the study abroad program. During this session faculty members review the information from the first orientation, have a presentation from our university's Center for Global Engagement that further addresses cultural issues and expectations, as well as information regarding cultural adaptation. The third orientation addresses research components of the trip, a standard packing and supply checklist, basic reservation information and a presentation by our host organization that discusses student expectations, family expectations, and rules and regulations that students must abide by while in India. It is important to note that during every orientation, students are shown pictures of the areas they will be living and working in while abroad. There are descriptions of the population, the terrain, the weather, the insects, the local food and many different trials and tribulations that students typically encounter as part of this program. In other words, it is made very clear that this will not be a vacation in paradise. 


\section{Field Work: The Case of "Donald"}

As noted, study abroad programs offer an exceptional opportunity for supervisors to assess students in many different aspects, including their participation and preparedness for fieldwork. The following is an example of one student ("Donald"- not his real name) who possessed the intellectual skills needed to complete his coursework in human services, and the foresight to work in administrative positions in all of his field placements prior to this study abroad program. However, after spending 5 weeks in India, it became clear to faculty and fellow students that Donald was neither willing nor prepared to work in communities with vulnerable populations. In fact, Donald was only able to successfully complete four days of on-site work due to a myriad of reasons.

One of the first indications that Donald might not have fully internalized the lessons from our orientation sessions came when, upon arrival in India, he began to complain that he really wanted a hamburger. He did not seem to be making a joke, or expressing an ironic desire to eat beef. He really seemed to be surprised that he would have a very difficult time procuring beef in a predominantly Hindu community. This was one of the things covered in several of our orientation sessions prior to leaving the United States, but these lessons appeared lost on Donald. In fact, he really did express shock that the majority of meals either provided for us or available at local restaurants consisted of local Indian cuisine. When asked by another student why he looked so unhappy with one of his first meals of the trip, Donald replied "I didn't think there would be this much Indian food."

Donald also expressed discomfort and frustration with the clothing norms at our field site in India. All students were asked to demonstrate a certain degree of cultural modesty while out in the community. Donald brought nothing but shorts on the trip, but needed to wear pants while working in public places. Upon arrival in India, Donald purchased one pair of white pants. He wore this one pair of pants, without properly cleaning them, throughout the entire trip. When the pants became damaged from wear and tear he continued to wear them while out in the community. On numerous occasions, faculty asked Donald to either buy another pair of pants or have his altered by the local seamstress. Even though the entire crotch was torn, Donald refused to replace or repair the pants. This became a running joke with the other students on the study abroad trip, as they began to relate to the days as "White Pants, Day 26."

Furthermore, students were required to blog weekly about their time in India. Most of the blogs were exceptionally insightful and demonstrated a profound level of self and community awareness. However, not only did Donald have to be "forced" to blog, but he rarely wrote about anything other than the food, bugs and heat that he "had to endure." In fact, one of our host organization's employees spoke with him regarding his post and said to his faculty supervisors and to Donald that "he did not get India at all."
These cultural foibles of Donald's may have been dismissed as merely awkward and amusing if they did not carry over into negatively impacting our relationships with members of the community we were trying to serve. Donald was assigned to work in a Muslim preschool. During his first day of work, students and faculty supervisors noted that Donald appeared extremely disengaged, bothered and bored with the children and the activities. Faculty supervisors noticed his troubling behavior and immediately removed him from the classroom to discuss the behavior. Donald reported he did not feel well and would try harder to engage. Nevertheless, it should be noted that the teacher working in the classroom asked fellow students if Donald liked children, indicating that he seemed quite uncomfortable around them. Donald was asked by faculty to take a few days off work and contemplate what he had to offer to this community, and specifically to the children. In hopes of remedying the problem, Donald was asked to continue meeting with the preschool team during planning sessions. However, at the next scheduled planning session Donald went to bed early. Faculty supervisors requested that everyone attend the meeting because it was important to understand the assessments being given to the children, as well as the teaching goals that were being implemented in the preschool. After a lengthy discussion with faculty, Donald did attend the meeting. However, he sat with his eyes closed, grimacing, rubbing his hands and face, and groaning, making it quite clear he was bothered by attending this meeting. He did not contribute, nor did he ask any questions about the materials.

After taking a week off work, Donald returned to the preschool where it quickly became apparent to faculty supervisors and his fellow students that he was unprepared and, in fact, unaware of what was expected of him. His task was to assess the children in his classroom using the Health Utilities Index. Although he was included in previous planning meetings and had the benefit of extra days to prepare, Donald was found preparing for the assessment during the morning circle time at the preschool. He did not bring the assessment copy he was given and had to ask another student if he could "look over" their assessment. Additionally, he asked other students to conduct the assessment on the children assigned to him so that he could "watch and learn." It should be noted that faculty prepared students, before leaving the US, on all assessments and again during all of the planning sessions while in India.

Donald continued to work in his assigned preschool over the next two days. He continued to be unprepared and chose not to implement the needed interventions in his classrooms. Other students reported that Donald was planning his intervention activities on the bus on the way to work. Planning this late left Donald feeling overwhelmed, unprepared, and left him with limited resources. Therefore, Donald employed no interventions. The teacher that Donald worked with indicated to faculty supervisors that she felt uncomfortable with him and stated she did not understand what support he was supposed to be providing. After 
numerous discussions with Donald, as well as with the educational director, faculty supervisors made the decision to remove Donald from the project in order to preserve the working relationship with the educational director and staff.

In addition to work expectations at the school, all of the study abroad students also conducted research within the community. Donald and his research partner conducted a home observation. His student partner was extremely bothered by Donald's behavior and reported to faculty that he revealed being uncomfortable with the number of insects in the home of the family they were observing. He continually swatted at flying bugs and moved around the home to try to avoid them. The partner stated this behavior made the homeowner embarrassed to the point of feeling the need to repeatedly apologize. It should be noted that the students were supposed to be conducting naturalistic observations, in which they needed to be as unobtrusive as possible. Students had received extensive training on this technique, being informed at length on the need and importance of being culturally sensitive and respectful of the participants. Due to his inability or unwillingness to follow our guidelines, Donald was also removed from the research portion of this project. His behavior was deemed potentially damaging to the relationship with the community members.

Donald's behavior continued to deteriorate throughout the remainder of the five weeks. He had to be reminded repeatedly by faculty to refrain from playing games on his phone during group meetings. He displayed disrespectful and offensive behavior toward other students, including an instance one evening during a card game in which he berated and insulted a female student for being "innocent" about adult topics and language. Several students stopped the game and confronted Donald. His only reply was that he "would like to corrupt [her] innocence before this trip is over." When faculty supervisors confronted Donald about his behavior, he made excuses and stated that he was "misunderstood."

Donald continued his inappropriate behavior by targeting another student who had a nose piercing and told her "I hate people with nose rings. It makes me want to put a leash through the ring and lead you around by it." Faculty members immediately reminded Donald of the purpose of this trip, to become aware of misogynistic ideals that perpetuate violence toward women. Nevertheless, Donald made excuses for his behavior and indicated that again he felt misunderstood.

Several female students throughout the trip said Donald made them feel exceptionally uncomfortable. They recounted, among other things, his detailed descriptions of previous sexual behavior with his ex-girlfriends and his unsympathetic attitude toward the children and women we were working with in India. He stated that he did not like children and was attending this trip only to graduate a semester early.

Donald's behavior was not only noticed by students and faculty, but also by our host organization's staff. During our Sex Trafficking Awareness Conference, Donald demonstrated an unwillingness to engage and contribute. He often appeared to be sleeping or extremely bored. When one presenter actually made a joke about the look of boredom on Donald's face, he just stared at her non-responsively. During the same conference, there was a group activity in which teams were asked to present information about trafficking. Donald contributed no information and refused to participate. His refusal was relayed to faculty supervisors by the owner of our host organization.

Donald demonstrated a complete lack of empathy, a poor attitude, an unwillingness to engage, a distaste for working with vulnerable individuals, and an inability to listen actively and pay attention to what was going on around him. However, upon return, faculty supervisors were unable to discipline Donald properly or in a meaningful way for his behavior because, at that time, the department did not have a Fitness for the Profession statement in place. This was profoundly frustrating and disturbing for faculty and administrators alike. Unfortunately, because he went on the trip, and was given alternative assignments on site that he completed, Donald was allowed to graduate from the program a semester early. Nevertheless, this incident motivated the human services faculty to adopt a Fitness for the Profession Statement and quickly incorporate the statement into departmental policies.

\section{Implementing a Fitness for the Profession Policy}

Service Learning provides students the opportunity to understand the philosophy and administrative strategies within day-to-day operations of organizations. These opportunities are certainly beneficial components of student learning. However, to only evaluate students' performance in the field using traditional classroom-based methods would not be effective, as certain aspects of service learning performance do not fit classroom expectations. Service Learning is an opportunity to benefit both academically and personally, and should be treated as such by students. Therefore, faculty supervisors must evaluate students based on their professional behavior and personal attributes in order to gain information about students' abilities to demonstrate effective communication skills, tolerance of others and of ambiguity, and overall cultural competence. Additionally, our program emphasizes the students' development of a commitment to social justice, and of aspects of overall wellness, such as emotional stability, self-acceptance, self-awareness and self-insight. We work to develop students as whole people, in addition to developing their academic and life skills. Our belief is that this type of development not only benefits individual students, but also benefits anyone they have contact with in their personal or professional lives.

The Fitness for the Profession statement is an integral part of any human services program, as it allows students to thoroughly understand what is expected of them throughout 
the academic program and during the course of a career within the human services field. Currently, in order to graduate from our human services department a student must demonstrate academic competence, exhibit commitment to the profession, and display ongoing personal growth. Assessment of personal growth takes into account personal and emotional characteristics, cooperativeness with others, willingness to accept and utilize constructive feedback, awareness of a student's own impact on others, their ability to deal with conflict, their ability to accept personal responsibility, and their ability to follow ethical and legal considerations that establish successful performance in the field of human services.

It is the objective of our human services department to recognize concerns regarding student aptitude as early as possible and to begin remediation when warranted. Students who display concerning behavior can be identified in the classroom as well as in their service learning placement, or at any time during their matriculation in the program. When concerns arise, faculty members are asked to report their concern to the Human Services Retention Committee. It is then the responsibility of the committee to bring the concerns to the student's attention. Once the student is notified, they are asked to schedule an appointment with either the field placement coordinator or their advisor in order to complete a remediation behavioral plan. The student is then given time to follow the behavioral plan and resolve their problematic behavior.

When the committee believes a student is not making sufficient progress toward goals included in their behavioral plan, members consult with the Department Head for input. With departmental approval, the student will be placed on behavioral probation and presented with further recommendations for remediation. If the recommendations are followed on an agreed-upon timeline, this will result in a decision to recommend removal of the student from probation. However, if a student fails to remediate, the committee may recommend voluntary termination from the program or recommend the student's dismissal to the Dean. Nevertheless, at any point during a student's academic career with the human services program, if the committee deems a student to be a harm to themselves or others, immediate termination from the program may be recommended.

\section{Conclusions}

Had our current Fitness for the Profession policy been in place within our human services program during the case of Donald's study abroad field experience in India, he could have been placed on probation and his graduation could have been postponed in order to determine if his personal aptitude and behavior were competent, and deserving of a human services bachelor's degree. The situation with Donald was extremely vexing for both the faculty supervisors, as well as for department administrators. To withstand the behavior and cultural incompetence that Donald displayed while on this study abroad trip, and then to watch as he prepared for graduation with no recourse, was unacceptable and exasperating. Part of the problem we faced was our lack of a formal, written record of our concerns about Donald prior to his India experience. In hindsight, several faculty members had experienced reservations about Donald's cultural competence among his classroom peers. With systematic documentation of these concerns, Donald may never have received the necessary approval to embark on international service learning with such vulnerable people. We may have extrapolated that Donald's cultural incompetence was likely to manifest as multicultural incompetence, away from his home environment. While other students with relatively little travel experience experienced culture shock in India, they also adapted and described their study abroad experience as life-changing. When Donald returned, he continued to talk about the bugs.

Despite the frustration our department experienced over the situation with Donald, it motivated the human services program to complete writing the Fitness for the Profession policy and to institute it so that in situations where students clearly are not making progress toward cultural competence and personal aptitude, there is some type of appropriate course of action. This is vital, given that so many human service professionals work with some of the most vulnerable members of our society.

\section{REFERENCES}

Davis, D. J., Major, A., Cook, D., \& Bell, J. (2015). Women Educational Leaders' Narratives: The Dynamics of Service Learning on Training and Transformation. International Journal of Progressive Education, 11(3), 64-76.

Earnest, D.R., Rosenbusch, K., Wallace-Williams, D., and Keim, A.C. (2016). Study Abroad in Psychology: Increasing Cultural Competencies through Experiential Learning. Teaching of Psychology, 43(1), 75-79

Edmonds, M.L. (2011). An Integrative Literature Review of Study Abroad Programs for Nursing Students. Nursing Education Perspectives, 33(1), 30-35

Hovland, K. (2010). Global Learning: Aligning Student Learning Outcomes with Study Abroad. The Center for Capacity Building in Study Abroad.

Krishnan, L.A., Richards, A.R., \& Simpson, J.M. (2016). Outcomes of an International Audiology Service-Learning Study-Abroad Program. American Journal of Audiology, 25, 1-13.

Lee, M. (2011). Trafficking and Global Crime Control. London: SAGE

Institute of International Education. (2015). A Quick Look at U.S. Students Studying Abroad 2015. Retrieved from http://www.iie.org/Research-and-Publications/Open-Doors/Data/ Infographics 
Pope-Davis, D. B., Reynolds, A. L., Dings, J. G., \& Ottavi, T. M. Rasmussen, L.J., \& Sieck, W.R. (2015). Culture-general (1994). Multicultural competencies of doctoral interns at university competence: Evidence from a cognitive field study of professionals counseling centers: An exploratory investigation. Professional Psychology: Research and Practice, 25, 466-470

who work in many cultures. International

Journal of Intercultural Relations,

http://dx.doi.org/10.1016/j.ijintrel.2015.03.014

Wong, E.D. (2015). Beyond "It was Great"? Not so Fast! A response to the argument that study abroad results are disappointing and that intervention is necessary to promote students' intercultural competence. The Interdisciplinary Journal of Study Abroad, XXVI, 121-135. 